\title{
上下・回旋斜視患者における偏位角測定値の検討
}

\author{
窪田 真実・木村亜紀子・目黒 千章・間原 千草・佐野 直子 \\ 田中 麻紀·三村＼cjkstart治
}

\author{
兵庫医科大学 眼科学教室
}

\section{Examination of the Measurements of Vertical and Cyclo Deviations in the Patients who have Vertical or Cyclo Strabismus.}

\author{
Mami Kubota, Akiko Kimura, Chiaki Meguro, Chigusa Aihara, Naoko Sano, \\ Maki Tanaka, Osamu Mimura
}

Department of Ophthalmology, Hyogo College of Medicine

\begin{abstract}
Purpose: The angles of vertical and cyclo deviations measured by a synoptophore are very important data to decide on the course of treatment. However, we sometimes had the fact that the data by the synoptophore varied according to other measurement methods.

So we studied the difference of data between the afferent and centrifugal methods.

Subjects: Forty-seven patients with vertical and/or cyclo strabismus, and 23 controls of good visual acuity without strabismus were investigated in this prospective study.

Methods: Each subjective angle at their primary position was first measured by the centrifugal method of moving the tube outwards on the synoptophore. Next, the tube of the synoptophore was moved far away from the position corresponding with the centrifugal data and then we measured the subjective angle again by afferent pathway approaching behind far point. We defined the difference in data between two methods as the dissociation.

Results: The dissociations of the cyclo deviations were significantly larger than those of vertical deviations between the strabismic subjects and the controls. The vertical dissociations of the strabismic group were significantly larger than those of the control group, especially, those of thyroid-associated ophthalmopathy (TAO) subjects and decompensation superior oblique palsy (decompensate SO palsy) subjects. No significant difference was detected between the strabismic group and the control group.

Conclusion: The results suggest that the dissociation of data between the afferent and centrifugal methods may be more associated with the stability of eye position than with the ability of binocular fusion. We recommend that careful measurements of vertical and/or cyclo deviations be performed in patients with strabismus, particularly those with TAO and/or decompensate SO palsy.
\end{abstract}

別冊請求先（广663-8131）兵庫県西宮市武庫川町 1 番 1 号

兵庫医科大学病院眼科医局

Tel. 0798 (45) $6111 \quad$ Fax. 0798 (45) 6464

E-mail : akis@hyo-med.ac.jp

Key words :

synoptophore dissociation, vertical straismus, cyclotropia 


\section{I．緒言}

大型弱視鏡は水平、上下、回旋成分の偏位角 を同時に測定でき、しかも正面視だけでなく 9 方向むき眼位での偏位角も測定可能な臨床上有 用な機器である ${ }^{1)}$ 。特に上下、回旋偏位の測定 值は治療方針決定の上で、非常に重要なデー夕 となる。しかし、通常の遠心法での測定值だけ では、交代プリズムカバーテストやHess赤緑試 験などの他の検査結果との間に測定值のばらつ きをみることがあり、当院では日常生活で重要 な正面視と下方視において、遠心法だけでなく 求心法での測定も行っている。今回、この上下、 回旋偏位の測定を遠心法と求心法で求め、得ら れた值の差（乘離）について検討した。

\section{II . 対象及び方法}

最近 1 年間に兵庫医科大学病院眼科で、上下、 回旋斜視と診断された斜視手術の既往のない 47 例（男性26例、女性21例）、平均年齢53.5歳（17 〜 7 5歳）を対象とした。内訳は表 1 に示した。 対照群には矯正視力が良好で（0.8以上）斜視の ない23例（男性 2 例、女性21例）、平均年齢37.8 歳（23〜 69歳）を用いた（表 1 ）。

方法は大型弱視鏡（Clement Clark社製）で、 第一眼位での自覚的斜視角を十字スライドを用 いて測定した。十字スライドで測定困難なもの には車庫と車のスライドを用いた。固視眼は斜 視群では健眼とし、対照群ではhole in card法に て決定した優位眼とした。

測定はまず遠心法による通常の測定法で行っ
た。次に得られた值からさらに大きく、上下、 回旋同時に鏡筒をずらしておき、そこから求心 的に同時視の得られる值を測定した。例えば上 方にずれた場合はさらに鏡筒を上方にずらして おき、そこから 0 度方向に向かって下方に鏡筒 を戻しながら、初めて同時視の得られる值を求 めた。下方ずれ、外方回旋ずれ、内方回旋ずれ も同様に、ずれた方向へさらに鏡筒をずらした ところから 0 度方向に向かって戻しながら同時 視の得られる值を求めた。

遠心法で得られた測定值と、求心法で得られ た測定值の差（絶対值）を乘離とした。乘離は 3回測定し平均值を用いている。

また、遠心法でずれが検出されなかった者に 対しては、上下は両側から、回旋は外方回旋側 から鏡筒をずらしておき、そこから求心的に測 定した。

\section{III. 結 果}

上下偏位の乘離において、斜視群は $0.90 \pm$ $0.92^{\circ}$ 、対照群は $0.32 \pm 0.33^{\circ}$ であり、回旋偏位の 乘離においては斜視群が $1.94 \pm 1.59^{\circ}$ 、対照群は $1.63 \pm 0.83^{\circ}$ であり、対照群、斜視群ともに回旋 の乘離は上下の乘離より有意に大きい。上下の 乘離において、斜視群では有意に対照群より大 きく、回旋の乘離では有意差を認めなかった （図 1、p=0.0205, Mann-Whitney's U test)。 上下偏位の乘離における各群での検討では、対 照群は $0.32 \pm 0.33^{\circ}$ であり、ほとんど乘離がみら れなかったのに対し、斜視群では乘離は有意に 大きい結果となった（図 2 ）。甲状腺眼症（以

表 1 対象の内訳

症例数（男性:女性）平均年齢 (歳)

\begin{tabular}{|c|c|c|}
\hline 後天滑車神経麻瘒 & $21(13: 8)$ & $57.8(22 \sim 75)$ \\
\hline 甲状腺眼症 & $12(6: 6)$ & $59.2(30 \sim 75)$ \\
\hline 代償不全性上斜筇麻盘 & $3(3: 0)$ & $24.3 \quad(17 \sim 31)$ \\
\hline 動眼神経麻㾇 & $7 \quad(4: 3)$ & $54.0 \quad(37 \sim 68)$ \\
\hline 筋無力症 & $4(0: 4)$ & $34.8(32 \sim 38)$ \\
\hline
\end{tabular}




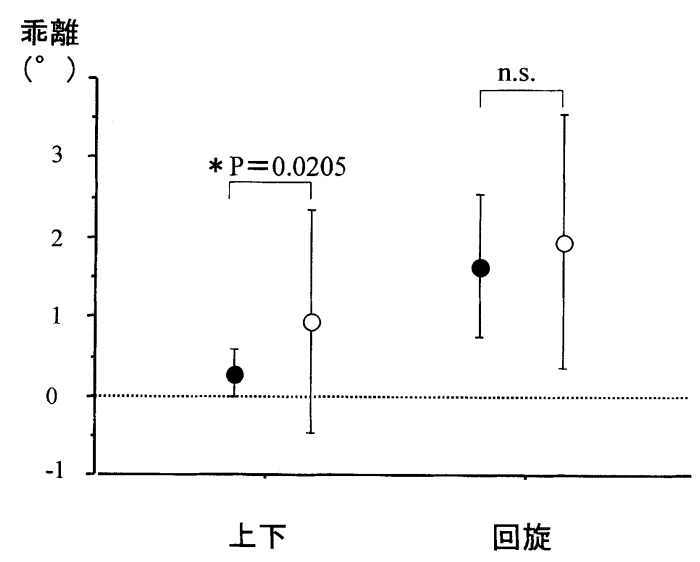

図 1 上下·回旋偏位の乘離

-対照群、○斜視群

対照群、斜視群とも回旋の乘離は上下の乘離 より有意に大きい（対照群：P=0.0001、斜視 群 : $\mathrm{P}=0.0002$, Paired t-test)。

上下の乘離は対照群に比べて斜視群で有意に 大きい（ $* \mathrm{p}=0.0205 ）$ が、回旋の乘離では有 意差は認めない (n.s.: not significant, $\mathrm{P}=0.8363$, Mann-Whitney's U test)。

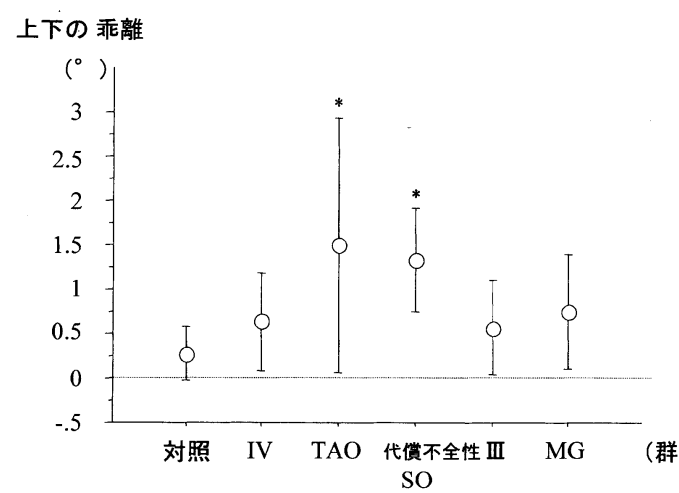

図 2 上下偏位の乘離 各群での比較 甲状腺眼症群と代償不全性上斜筋麻瘏群で有 意差がみられた（ $\mathrm{p}=0.0011$, Kruskal-Wallis test）。斜視群は全群が対照群を上回った。

下TAO）群では $1.50 \pm 1.34^{\circ}$ 、代償不全性上斜筋 （以下SO）麻痺群で $1.33 \pm 0.66^{\circ}$ と大きく、他の 斜視群、滑車神経 (IV) 麻瘦群 $0.64 \pm 0.52^{\circ}$ 、動 眼神経 (III) 麻瘏群 $0.57 \pm 1.42^{\circ}$ 、筋無力症（以 下MG）群 $0.75 \pm 0.56^{\circ}$ との間にそれぞれ有意差を 認めた（P=0.0011, Kruskal -Wallis test $)$ 。回旋 偏位の乘離は対照群 $1.63 \pm 0.83^{\circ}$ であり、斜視群 $1.94 \pm 1.59^{\circ}$ で有意差は認めなかった。
IV 麻痺群は $1.74 \pm 1.80^{\circ} 、 \mathrm{TAO}$ 群は $2.50 \pm 1.53^{\circ}$ 、 III麻痺群は $1.43 \pm 1.97^{\circ} 、 \mathrm{MG}$ 群は $2.38 \pm 2.16^{\circ}$ 、代 償不全性SO麻痺群は $1.67 \pm 0.80^{\circ}$ であった。

斜視角の大きさと上下偏位の乘離、回旋偏位 の乘離については相関はみられなかった(図 3)。

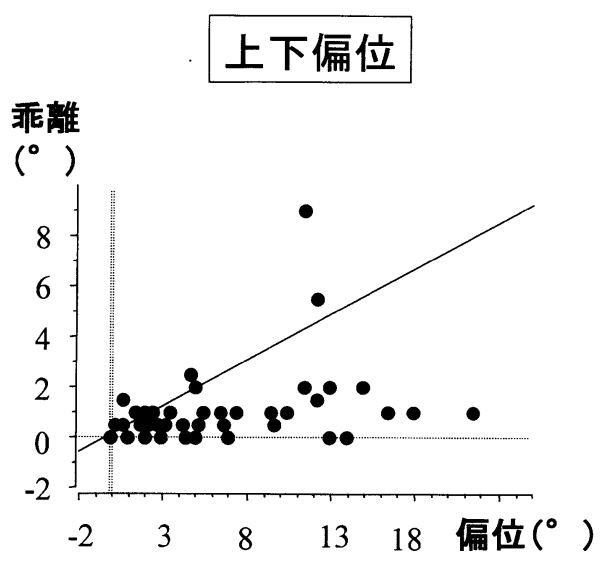

\section{回旋偏位}

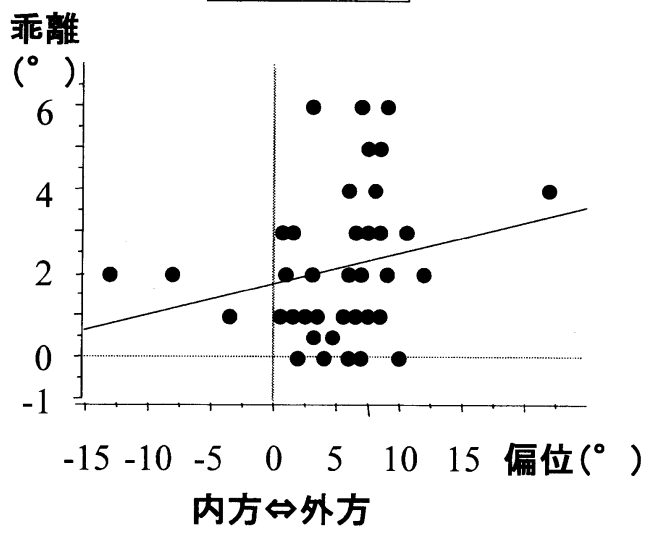

図 3 偏位角と乘離の相関

左：上下偏位の乘離 $\mathrm{R} 2=0.089$ 相関なし

右：回旋偏位の乘離 $\mathrm{R} 2=0.044$ 相関なし

\section{IV. 考按}

正常者ではある一定の上下・回旋に対する融 像域をもち、上下は $1 \sim 2^{\circ}$ と小さく、回旋は約

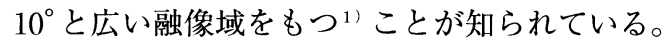
乘離は大型弱視鏡を用いて遠心的と求心的に上 下・回旋偏位を測定した時に認められる検査上 の不一致性を表している。対照群の上下の乘離 
は $0.32 \pm 0.33^{\circ}$ 、回旋の乘離は $1.63 \pm 0.83^{\circ}$ であり、 正常者では上下偏位、回旋偏位ともに融像域と 比較すると乘離は非常に小さい值で認められる。 乘離は検查上、測定值として現れる不一致性と 捉えられる。上下の乘離において、融像域が広 いTAO、代償不全性SO麻痺の 2 群において乘 離は有意差をもって大きい值をとることから、 融像域が広いと検查上、測定值として不一致性 （=乘離）が認められると考えた。一般的に、 上下偏位は水平偏位と異なり、融像域が約 1 〜 $2 \circ$ と小さいことからわずかな上下偏位に対して もプリズム療法などを必要とすることが知られ ている2)。TAOと代償不全性SO麻痺は上下偏位 が徐々に生じ、長い時間をかけてそれに適応し てきた疾患であり、乘離が顕著に現れたと思わ れる。

一方、回旋偏位の乘離は正常者でも認められ、 また上下偏位の乘離より有意差をもって大きい ことは、回旋融像を保持する成分がやはり感覚 性融像主体であるため、検查上測定値としては 乘離として認められるのではないかと考えた。 回旋の乘離はTAO群とMG群で大きな乘離（有 意差はなし）を呈する傾向にあったが、TAOで は上下の機械的運動障害を生じることが多く、 眼球運動制限があるにもかかわらず2) 3) 感覚融 像により融像域は広く、MG群では徐筋機能は 保たれている ${ }^{4)}$ ため、感覚融像がなされている ためと考えた。乘離は対照群では斜視群に比べ
て小さい值を示した事から（上下は有意差有り、 回旋では有意差なし)、乘離の大小は眼位の安 定性を示す指標となる可能性もある。

今回の結果から、上下・回旋斜視では、回旋 偏位より上下偏位に関して乘離が大きく現れる 事から、測定法の違いにより上下偏位の測定值 にばらつきがある事がわかった。どちらの測定 值が手術時の参考になるのか、他の諸検査と見 比べて妥当な測定值なのかは今後の検討課題で あるが、上下偏位の測定時にはある一方だけの 測定值だけで治療方針を決定するのは注意を要 すると考えられる。

乘離の測定は日常診療の現場で簡便に検査で きることから、症例数を増やし、乘離のもつ意 味を検討する予定である。

\section{参考文献}

1 ）山本裕子、新井牧恵：上下および回旋方向の 融像域について. 眼臨 69:1382-1384, 1975.

2 ）藤井啓誠：Graves病に伴う眼症状 第 2 報 外眼筋障害の臨床的解析と治療. 眼紀 37 ： $113-119,1986$.

3 ）向野和雄、富岡敏也、小川泰典：複視の病態 と治療.あたらしい眼科 $13: 1835-1841$, 1996.

4 ）青木繁、向野和雄 : 重症筋無力症と眼. 眼科 $30: 1235-1243,1988$. 